\title{
Innovation-driven development and quality of living under conditions of digital economy
}

\author{
Natalya Gagulina ${ }^{1}$, Alexander Samoylov ${ }^{2}$, Andrey Novikov $^{3 *}$, and Elena Yanova ${ }^{4}$ \\ ${ }^{1}$ Institute for Regional Economic Studies, 190013, 38 Serpuhovskaya str., Saint Petersburg, Russia \\ ${ }^{2}$ State University of Aerospace Instrumentation, 190000, 67 Bolshaya Morskaya str., Saint Petersburg, \\ Russia. \\ ${ }^{3}$ Saint-Petersburg State University, Faculty of Economics, 191194, 62 Tchaikovskogo str., Saint \\ Petersburg, Russia \\ ${ }^{4}$ ITMO University, 197101, 49 Kronverksky avenue, Saint Petersburg, Russia
}

\begin{abstract}
The spread of digital innovation in the world began in the 1960s. and the first stage came down to the automation of technologies and processes. The next stage came in the mid-90s. and is associated with the global spread of the Internet and mobile communications, the extensive penetration of innovation into society. The current stage of innovationdriven development is characterized by the expansion of Internet access of millions of consumers, the integration of wide range of digital services, products, systems into the digital socio-ecological and economic system. The ongoing revolutionary changes deserve additional understanding and analysis, since they give to many countries such impetus for rapid growth that they change the very paradigm of development, and force them to measure and evaluate the life quality in a new way. In the context of problems covered in this article, it is especially relevant to conduct a causal analysis of digital transformation against the background of global transformations of the world economy.In the process of analyzing innovation as a tool for the development of public production, the authors identified the drivers of digital economy, determined their role at the present stage, and showed their distinctive aspects and features.
\end{abstract}

\section{Introduction}

The digital economy is confidently entering the life of modern society, which is accompanied by global transformations, accelerated implementation of innovations in public administration processes, in the business work and, to a large extent, in the everyday people life. The objectives of the National Program "Digital Economy of the Russian Federation" reflect well the priorities that Russian society is oriented to in the context of global transformations: Internet access for everyone, 5G communication coverage of the largest cities, data protection of citizens, business and the state, growth in the efficiency of key industries through the introduction of new technologies, training for the future based on endto-end digitalization, stimulating investment in new areas while increasing development costs 
digital economy. These goals are in good agreement with the increasing importance of life quality as a priority factor in ensuring the competitiveness of the national and regional economies, and increasing their investment attractiveness.

In this regard, the issues related to the study of relationship between innovative development and life quality become acute.

\section{Global transformation and digital economy}

Digital transformation of the economy is understood as the manifestation of qualitative, revolutionary changes, consisting not only in individual digital transformations, but also in fundamental change in the economy structure, in the transfer of value-added centers to the sphere of building digital resources and end-to-end digital processes [1].

The digital transformation of the economy at the present stage of scientific and technological development is a natural process that has become a manifestation of systemic changes in the economy. The evolution of economic systems is always accompanied by transformation. Currently, this is a process of planetary scale, affecting almost the entire world economy. Global transformations are associated with transformation of civilization space and change in the content of its key components - socio-demographic, naturalecological, economic, geopolitical, socio-cultural and technological [2].

Among the main reasons for the rapid digital transformation with features of its global distribution, both economic and technological changes are noticeable:

- the growth of worldwide informational "inclusion" exponentially - due to a decrease in the cost of connecting to information networks;

- the growth of computing power, accompanied by decrease in the main types of costs;

- the emergence of cheap tools and methods for storing large volumes of wide variety of data;

- applicability of advanced technologies in the context of large data arrays;

- using the ability to process raw data at the level of the ordinary consumer.

The digital transformation often manifests itself in a change in the institutional foundations of economic system and its values, which affects state authority of states and changes their significance in the international arena [3]. It is already shaped the new technological structure, whose formation is accompanied by the emergence of new economy sectors. The economy itself is changing, becoming digital in essence, which means the priority of production and use of accumulated information and advanced information and communication technologies in order to ensure the growth of efficiency of all other forms of production and to improve the life quality of population. The whole economy structure begins to be rebuilt in the direction that most effectively enable to process information.

Researchers identify seven evolutionary-informational stages of development due to the emergence of the relevant types of information technologies: spoken, written, typographic, radiotelegraph, computer, computer material-network, global quantum-field or computer personified-network [4]. The emergence of meaningful speech and language as generally accepted means of communicative communication between people in society marked the emergence of oral-speech technology for transmission and reproduction of appropriate data, using people as media. The data transfer using symbolic media (symbols, signals, signs, manuscripts) is associated with the emergence of writing and grammar rules. The advent of printing allowed the transfer and reproduction of useful data using bookish media (letters, books). Radio telegraph technology is associated with the emergence of electromagnetic technologies for data transmission and reproduction, which is transmitted using various kinds of electromagnetic signals, being converted into visual-audio symbols by telegraph, telephone, radio, television. Due to this, the revolution took place in the speed and volume of information transmission, processing, production and accumulation. 
The invention of computer ensured the further spread of revolutionary changes in the way of processing and working with large volumes of data and information. Computer material and network technology has firmly entered the life of modern society in connection with the emergence and spread of computer, telecommunication and space communication networks and information transfer. Huge information flows are collected, processed and reproduced using computer networks and space satellite communications networks. The world wide computer network Internet and its constituents such as Broadband Networks, Enterprise Networks, Public Carrier Networks, Wireless Networks, have pushed humanity to enter the initial phase of the information society.

In the years ahead, non-material (digital) quantum-field technologies for data transmitting and reproducing (for example, quantum computers connected to their personalized media and integrated into a global quantum network) will allow formation and development of global worldwide computer-telecommunication quantum-field supernetwork for collection, processing, production, accumulation and use of appropriate information throughout the world and in all spheres of human life. Hypothetically, this creates the prerequisites for the implementation of global management and global control over information processes. At this stage, we can talk about the completion of transition of human civilization to mature stage of its information development: stages of mature information society.

Digitizing information technology, i.e. presentation of objects and phenomena of the surrounding world with help of encoded information in a certain way, having a digital (sign) form, which is most convenient for computer processing, programming and transmitting via network channels back to object with new specified properties, is a overall universal way to transform real-world phenomena and programming system parameters of their future development at the present stage of socio-economic development [5]. The most modern and effective technologies are based on the principle of digitizing the wide variety of objects (image, sound, data, books, money, etc.).

Thus, the concept of "digital economy" quickly came into use and in broad sense means the digital transformation of the entire field of socio-economic interaction with the leading role of digital technology. The digital economy in the narrow sense means the digital sector of the national economy.

The digital economy gives the active role ensuring for each macroeconomic entity in accordance with its objective function. The simplest interpretation of macroeconomic model presented in Figure 1 involves ensuring the future competitiveness of companies, industries and national economy as a whole, through large-scale investments in the following priorities: - the state-owned formation of advanced high-tech digital infrastructure accessible and in demand by all participants in economic relations;

- $\quad$ accelerated creation and implementation by the business of advanced digital technologies and high-tech industries that ensure the country's competitiveness at the world level;

- $\quad$ raising the level of digital culture and population literacy, mastering the majority of population with advanced technologies and using the basic links of digital infrastructure, which will not only lead the country into the leaders of the global economy in terms of digitalization, but also create the basis for sustainable development in the future. 


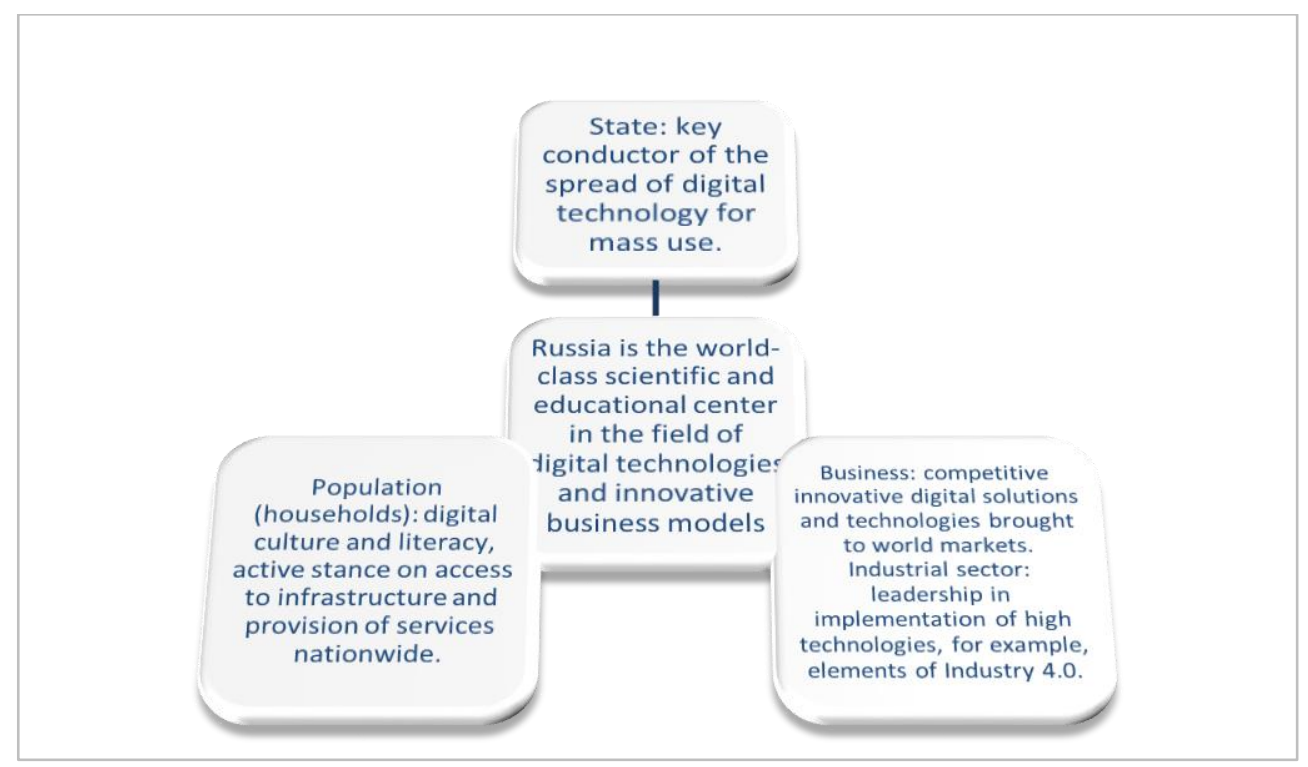

Fig. 1 The simplest interpretation of macroeconomic model for digital economy.

The identified investment policy priorities are caused by the epoch-making changes that are taking place due to digital transformation in the context of globalization.

Entire industries in Russia and in the world are transforming in connection with the accelerated development of the digital economy [6]. Among the industries that have undergone the fastest development under the influence of digitalization are retail trade (Amazon.com), taxi (UBER, Yandex taxi), ticket sales and tour operators (Booking.com, skyscanner) and many others [7]. Significant role in this process belongs to the drivers of innovation-driven development: digital assets.

\section{Drivers for innovation-driven development of the digital economy}

The most valuable assets at the present stage include digital platforms. Significant activity in this direction is shown by companies building extensive channels of network interaction: Facebook, iTunes, eBay, Amazon, LinkedIn, Airbnb, Tencent, VKontakte, Yandex, Avito, OZON. Digital platforms are starting to be used not only as the main channels of interaction with customers, but also as means of conducting transactions, instrument for creating innovative business models, and even traditional industries in this sense are no exception. In order to increase sales, both intermediaries and manufacturers can take into account information about individual preferences that remain online when potential buyers use digital platforms to compare products online before buying.

The main reason for rapid development of digital assets is the huge economies by scale. The era of digitalization has no need to build large production complexes, which requires significant investment of time and resources and is associated with large marginal costs. Digital companies are characterized by combination of low marginal cost and good scalability of IT platforms. This creates conditions for the most successful companies to achieve economies of scale in unprecedented amounts in record time. Such economic advantages ensure high profitability for software developers, reaching more than $70 \%$ [8]. This is convincingly evidenced by the rating of the most expensive companies in the world, in which for several years more than $50 \%$ has been accounted for by companies that use 
digital assets (table 1). The table is compiled by the authors based on [9] as of January 20, 2020.

Table 1. Rating of the most expensive companies in the world in terms of market capitalization.

\begin{tabular}{|c|c|c|c|c|}
\hline Item No. & Company & $\begin{array}{l}\text { Scope of } \\
\text { activity }\end{array}$ & Product Range & $\begin{array}{l}\text { Market } \\
\text { capitalization, bln } \\
\text { dollars USA }\end{array}$ \\
\hline 1. & $\begin{array}{l}\text { Saudi Aramco } \\
\text { (Saudi Arabian } \\
\text { Oil Company) }\end{array}$ & $\begin{array}{l}\text { Oil and gas } \\
\text { extraction and } \\
\text { refining }\end{array}$ & $\begin{array}{l}\text { Oil, natural gas and other } \\
\text { petrochemical products }\end{array}$ & 1880 \\
\hline 2. & Apple Inc. & $\begin{array}{l}\text { Electronics, } \\
\text { information } \\
\text { technology }\end{array}$ & $\begin{array}{l}\text { Personal computers and tablets, } \\
\text { mobile phones, audio players }\end{array}$ & 1397 \\
\hline 3. & Microsoft & $\begin{array}{c}\text { Software } \\
\text { development }\end{array}$ & $\begin{array}{l}\text { Microsoft Office, Microsoft } \\
\text { Windows, Xbox }\end{array}$ & 1274 \\
\hline 4. & Alphabet Inc. & Internet & $\begin{array}{l}\text { Internet services, applications, } \\
\text { video hosting and much more }\end{array}$ & 1020 \\
\hline 5. & Amazon Inc. & Retail sales & $\begin{array}{c}\text { Sale and delivery of goods over } \\
\text { the Internet }\end{array}$ & 924,52 \\
\hline 6. & Facebook & Internet & Internet projects, advertising & 633,49 \\
\hline 7. & Alibaba Group & Internet & $\begin{array}{l}\text { E-commerce, hosting of online } \\
\text { auctions, online money transfers, } \\
\text { mobile commerce }\end{array}$ & 610,13 \\
\hline 8. & $\begin{array}{c}\text { Berkshire } \\
\text { Hathaway Inc. }\end{array}$ & $\begin{array}{l}\text { Insurance, } \\
\text { finance, } \\
\text { railways, } \\
\text { utilities, } \\
\text { production of } \\
\text { food and non- } \\
\text { food products }\end{array}$ & $\begin{array}{l}\text { Services and products by } \\
\text { company activities }\end{array}$ & 562,39 \\
\hline 9. & Tencent & \begin{tabular}{|c|} 
Venture \\
company, \\
conglomerate, \\
investment \\
holding, gaming \\
industry \\
\end{tabular} & $\begin{array}{c}\text { Social networks, instant } \\
\text { messaging, media, web portals, } \\
\text { etc. }\end{array}$ & 492,9 \\
\hline 10. & Visa Inc. & $\begin{array}{c}\text { Financial } \\
\text { services }\end{array}$ & $\begin{array}{l}\text { Payment transactions and bank } \\
\text { transfers between financial } \\
\text { institutions, to a large extent - } \\
\text { using the VisaNet electronic } \\
\text { payment network }\end{array}$ & 441,61 \\
\hline
\end{tabular}

Digital platforms enable to collect, summarize, analyze and monetize information about users that previously was extremely difficult to obtain. This data is about behavioral features, about consumer preferences, which are necessary for building the strategy not only for business, but also for the state. According to SimilarWeb research, the top 100 world news and media sites` share of traffic redirected from social networks is $6.5 \%$. At the same time, the share of such traffic can reach up to $50 \%$ for sites that specifically adapt their content to users of social networks.

Digital assets are a concept closely related to the work of one of the main macroeconomic markets - the financial market, more than other markets involved in the digital transformation process. At the same time, the concept of digital assets is still vague and poorly defined both in scientific and in institutional context. Among the main reasons why there was a need for definition and institutionalization of digital assets, one can single out the use of blockchain 
technology in the economy financial sector. Russia is one of the leading countries in attracting investments in form of digital assets (Figure 2, constructed by the authors based on [10]). Maximum investment (about $\$ 1,100$ million) falls on the USA, the minimum to Estonia (about \$ 75 million dollars). In 2017, the Russian Federation invested more than \$ 300 million dollars in digital assets, which is about $11 \%$ of the global investment in digital assets.

Another group of problems is semantic problems. They relate to the composition and content of the concept of digital assets. Today, tokens, cryptocurrency and digital signs have been allocated as part of digital assets.

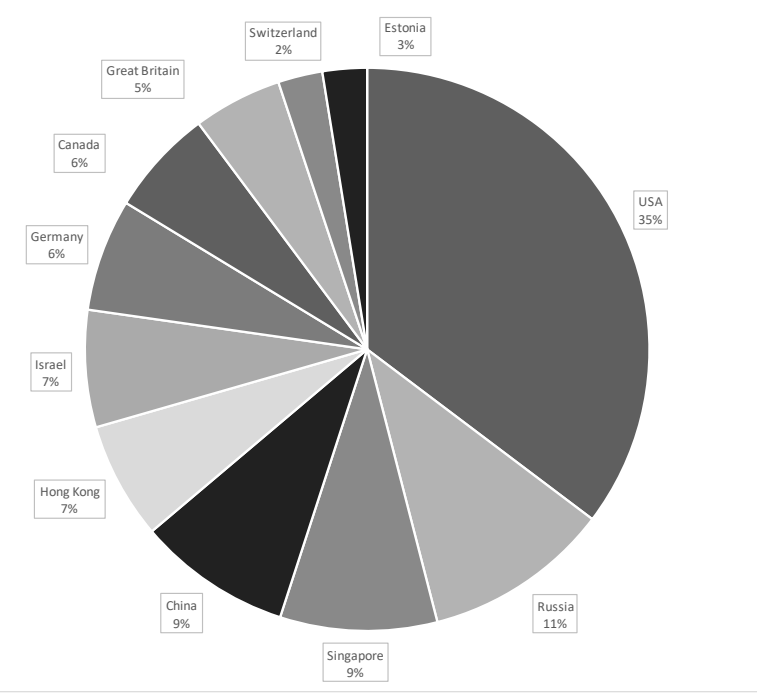

Fig. 2. Global investment in digital assets, \$ million dollars, 2017.

Tokens are digital assets that express obligations and other rights, whose exercise and transfer is possible only in compliance with the legislation on securities market. In practice, tokens are a broader concept than a security, as it expresses analogue of security or other financial instrument in the professional market.

Cryptocurrency is a digital asset used as a account unit, subject of sale, accumulation tools and exchange medium for goods and services in relations with indefinite number of people. Today, Bitcoin, Ethereum, Ripple and others can be distinguished among the leading cryptocurrencies. Table 2 shows the site data of investments in financial markets in cryptocurrencies [11]. As we can see, Bitcoin has the largest capitalization.

Digital signs are digital assets that do not fall under the concept of tokens and cryptocurrencies, and expressing property and other owner`s rights in the framework of civil contracts.

As part of digital signs, Utility token and Asset-backed token are distinguished today. Utility token is a way of expressing the value of special offers of online platform, such as bonuses, points, reputation, unique content, game currency and so on. Asset-backed token is digital obligation to exchange for real product or service.

Table 2. The main indicators of leading cryptocurrencies, 07.02.2020.

\begin{tabular}{|c|c|c|c|c|c|c|c|}
\hline Name & Ticker & $\begin{array}{l}\text { Price } \\
\text { (USD) }\end{array}$ & Outlet & Volume (24h) & Volume & Chg. (24h) & $\begin{array}{c}\text { Chg. (7 } \\
\text { days) }\end{array}$ \\
\hline
\end{tabular}




\begin{tabular}{|c|c|c|c|c|c|c|c|}
\hline Bitcoin & BTC & $9.908,2$ & $179,31 \mathrm{~B} \$$ & $38,81 \mathrm{~B} \$$ & $27,24 \%$ & $-2,03 \%$ & $+5,62 \%$ \\
\hline Ethereum & ETH & 223,97 & $24,39 B$ \$ & $16,21 \mathrm{~B} \$$ & $11,38 \%$ & $-1,33 \%$ & $+17,44 \%$ \\
\hline Ripple & XRP & 0,27588 & $11,96 \mathrm{~B} \$$ & $2,36 \mathrm{~B} \$$ & $1,66 \%$ & $-1,71 \%$ & $+9,25 \%$ \\
\hline Bitcoin Cash & $\mathrm{BCH}$ & 461,02 & $8,33 \mathrm{~B} \$$ & $4,61 \mathrm{~B} \$$ & $3,24 \%$ & $+3,46 \%$ & $+19,38 \%$ \\
\hline Bitcoin SV & BSV & 356,01 & $6,36 \mathrm{~B} \$$ & $3,24 \mathrm{~B} \mathrm{~S}$ & $2,27 \%$ & $+4,32 \%$ & $+23,91 \%$ \\
\hline Lightcoin & LTC & 74,968 & $4,76 \mathrm{~B} \$$ & $5,54 \mathrm{~B} \$$ & $3,89 \%$ & $-2,01 \%$ & $+6,56 \%$ \\
\hline EOS & EOS & 4,9402 & $4,64 \mathrm{~B} \$$ & $4,42 \mathrm{~B} \$$ & $3,10 \%$ & $+0,32 \%$ & $+15,48 \%$ \\
\hline Tether & USDT & 0,9997 & $4,63 \mathrm{~B} \$$ & $47,99 \mathrm{~B} \$$ & $33,68 \%$ & $+0,01 \%$ & $-0,37 \%$ \\
\hline Binance Coin & $\mathrm{BNB}$ & 24,933 & $3,87 \mathrm{~B} \$$ & $759.50 \mathrm{M} \$$ & $0,53 \%$ & $+7,86 \%$ & $+35,62 \%$ \\
\hline Tezos & XTZ & 2,584 & $1,85 \mathrm{~B} \$$ & $216,15 \mathrm{M} \$$ & $0,15 \%$ & $+6,73 \%$ & $+34,37 \%$ \\
\hline Cardano & ADA & 0,060238 & $1,55 \mathrm{~B} \$$ & $140,25 \mathrm{M} \$$ & $0,10 \%$ & $-1,67 \%$ & $+5,63 \%$ \\
\hline Monero & XMR & 85,663 & $1,49 \mathrm{~B} \$$ & $140,01 \mathrm{M} \$$ & $0,10 \%$ & $+1,31 \%$ & $+10,49 \%$ \\
\hline TRON & TRX & 0,021981 & $1,44 \mathrm{~B} \$$ & $1,51 \mathrm{~B} \$$ & $1,06 \%$ & $+0,28 \%$ & $+13,00 \%$ \\
\hline Stellar & XLM & 0,07082 & $1,42 \mathrm{~B} \$$ & $521,91 \mathrm{M} \$$ & $0,37 \%$ & $-2,22 \%$ & $+10,93 \%$ \\
\hline Ethereum & ETC & 11,9131 & $1,38 \mathrm{~B} \$$ & $2,87 \mathrm{~B} \$$ & $2,02 \%$ & $+2,64 \%$ & $+0,49 \%$ \\
\hline
\end{tabular}

Semantic problems are the root cause of institutional consolidation of "digital assets" concept. Vivid manifestation of these problems is the detailed elaboration of draft Law $\mathrm{N}$ 419059-7 "On digital financial assets and on amendments to certain of the Russian Federation legislative decrees" against the background of unavalable law "On digital assets".

To solve these problems, it is necessary balanced position of the authorities, business, investors and the expert community. In the long run, this will increase the investment attractiveness of the Russian Federation by strengthening the role of regulatory and coordination institutions, increase the amount of tax deductions to the budget due to transaction transparency and simplify the conduct of financial transactions for business.

\section{Life quality under digitalization conditions: pros and cons}

The most common and essential components of the concept of "life quality": health, food consumption, education, employment and labor organization, life amenities, social security, clothing, leisure and free time, human rights - are given in the UN recommendations. Throughout the millennia preceding the present, material values, which have priority for most people, were available to only a few. Today, when accumulated and processed knowledge and information embodied in the scope of innovations become the main value, more and more opportunities for improving the life quality for the majority of population are opening up [12].

The innovative nature of changes in the economy taking place in the era of digital transformation is due to technological changes in information and communication technologies that make up the most dynamic segment of digital economy. Activities related 
to the use of computer devices and information technology include software development, consulting, information processing, creation and use of databases and information resources, maintenance of computer equipment, etc. All of the above contributes to the growth of demand for development of science and technology, which inevitably affects the life quality.

It is innovations that give development a positive character and in the long run make it sustainable. Based on the experience of previous scientific and technological development, we can say that the modern digitalization of the economy is the forerunner of new scientific and technological revolution, which will lead to the creation of a new industry, known as "Industry 4.0".

Industry 4.0 is characterized by combination of intelligent manufacturing and information technology, that is, symbiosis of human and machine intelligence. According to the expectations of its engineers, the new industry will become a customized industry: each consumer will be able to contact the supplier and get exactly the product, service that suits him. Naturally, this means a significant improvement in the life quality, as it leads to a more complete satisfaction of existing needs. Simple example shows how deep the upcoming changes can be: Today, any smartphone can perform many functions - to be not only a communication media, but also a bank, a store, a TV, a clock, a camera and even a personal adviser (Alice, Siri). A person does not have to go to the store, stand in line at the ticket office for tickets, or go to the bank. All this can be done, as they say, "in one-touch".

In improving the life quality, a huge array of new opportunities for the majority opens up: Internet commerce, digital agriculture, smart grid systems, unmanned vehicles, personalized healthcare. The state, for its part, is developing projects that in the long run should ensure increase in the life quality. In Russia, it is planned to implement cross-cutting priority technologies for this within the framework of the national technological initiative: big data, artificial intelligence, distributed ledger systems, quantum technologies, new and portable energy sources, new manufacturing technologies, sensorics and components of robotics, wireless communications technologies, biological properties management technologies, neuro-technologies, virtual and augmented reality technologies [13]. Among the promising markets for their implementation are the markets presented in Table 3.

Table 3. Promising markets for national technology initiative

\begin{tabular}{|r|l|c|}
\hline \multicolumn{1}{|l|}{$\begin{array}{l}\text { Item } \\
\text { No. }\end{array}$} & Market Name & Key Feature \\
\hline 1. & AeroNet & Market for distributed unmanned aerial vehicle systems \\
\hline 2. & AutoNet & Unmanned vehicle market \\
\hline 3. & NueroNet & Human-machine communications market \\
\hline 4. & HealthNet & Personalized medicine market \\
\hline 5. & EnergyNet & Intelligent and distributed electric networks market \\
\hline 6. & SafeNet & Market for new personal security systems \\
\hline 7. & FinNet & Food decentralized financial systems and currencies \\
\hline 8. & FoodNet & all technology process stages: from production to consumption \\
\hline 9. & MariNet & Marine intelligent systems market \\
\hline
\end{tabular}

The level of services is complicated by combining previously disparate technologies, creating completely new approaches to the management of production processes and the environment [14]. Among the striking examples are PLM-systems (product/product life cycle management), BPM-systems (business process management). At the household level, people's lives are called upon to improve smart home, smart parking, smart locks and much 
more. It should be noted that the success of introducing new approaches is determined by many factors, among which are the attitude of society towards digital transformations, structural and institutional transformations, rethinking of relations between the state and business, new type of workflow management and new regulatory mechanisms.

Along with the growth of opportunities for satisfying individual needs and improving the life quality for the majority, one cannot but note the emergence and growth of serious problems caused by digitalization. First of all, this is a radical change in the situation on the labor market, associated with the withering away of number of professions and increasing demand in the sectors of Industry 4.0. Imbalance of supply and demand in high-tech sectors of the economy means the emergence of structural unemployment, which can only be covered if the personnel are trained appropriately and the continuing education system works well thanks to professional retraining and advanced training of specialists. Increase in structural unemployment can lead to drop in real incomes of the population and, as a consequence, to reduction in the investment opportunities of economy, which in the long run can provoke the life quality drop. Lack of investment severely limits opportunities for further digitalization and growth.

Against the background of reduction in transaction costs in the economy, increase in involvement of artificial intelligence in decision-making processes, risks and uncertainty, for example, in the financial market, which operates more than other markets with digital assets, in the context of digitalization may not decrease, but rather increase. The limitations of analytical models and platforms open the problem of finding new scientific theoretical and methodological approaches [15]. Sudden changes in the situation in virtualized markets against the background of identical or similar information processing techniques and decision-making technologies for most users can provoke a destructive "crowd effect" or panic.

Another problem is caused by the emergence of the digital divide in development and use of digital innovations both at the regional level and in the global economy. Example is different degree of readiness for the application and use of artificial intelligence technologies by corporations both in different regions and in different countries, and different level of digital literacy of population.

Herein is a far from complete list of problems that must be solved together, since the likely benefits of their solution clearly outweigh all the risks and possible threats.

\section{Discussion}

Digitalization of economic processes in connection with global transformations is becoming a comprehensive trend, covering not only the information and communication industry, but also all areas of economic activity. This is a natural and at the same time revolutionary process that is rapidly spreading and gives an additional impetus to the modern innovationdriven development of the economy.

The need for deep and systematic study of the relationship between the prospects of innovation-driven development and life quality is due not only to the advantages that appear related to transformation of the business environment, infrastructure, working conditions and people's livelihoods. First of all, the digital economy affects the fundamental foundations of civilization.

The dominance of information component in the global economy, politics and ideology is changing the lifestyle and content of relationships in all key areas. As the digitalization of economy intensifies, new risks and threats arise due to the specific properties of information as a resource, as a product of activity, and as a subject of economic interaction. The problems identified by the authors are not limited to particular problems, which include, for example, ensuring cybersecurity in conditions of cross-border transmission of information and the 
operation of most servers. In conditions when new entities and phenomena become drivers of digital development, it is extremely necessary to specify their conceptual framework and institutionalize them. Using the economy of quality will improve their management efficiency and achieve better results at all levels [16]. To a large extent this applies to digital assets, which today provide significant economies of scale for most successful companies.

In order to minimize the associated undesirable results of the economy digital transformation, it seems advisable to develop new theoretical and methodological approaches in the field of digital asset management that will expand individual cognitive capabilities and allow, when making complex management decisions, significant amount of accurate and reliable information.

\section{Conclusion}

The epochal changes occurring in connection with the digital transformation in the context of globalization open up enormous opportunities for the qualitative improvement of not only industrial technologies, but also a number of areas of economic activity, improving the living conditions of population, and improving the life quality. The emergence of new technological trends and economic categories, which include digital assets, inspires particular optimism. Cross-industry changes give impetus to the emergence of digital platforms amid the convergence of businesses from various industries, the introduction of end-to-end digital processes for the transition of all vital areas of social life to new digital mechanisms. At the same time, the practical implementation of technological trends in digital transformation is difficult without scientifically sound approach that combines the high requirements for both the level of scientific and technological development and the life quality of population. Such an approach may be the combined use of the quality economy and the methodology of agentbased models, which has repeatedly confirmed the relevance in the scientific community and its practical importance.

\section{References}

1. V. Ranta, J. Keränen, L. Aarikka-Stenroos, How B2B suppliers articulate customer value propositions in the circular economy: Four innovation-driven value creation logics, Industrial Marketing Management. https://doi.org/10.1016/j.indmarman.2019.10.007

2. N. Gagulina, A. Budagov, A. Novikov, E3S Web of Conferences, 110, 02108, (2019). https://doi.org/10.1051/e3sconf/201911002108

3. N. Gagulina, I. Zhulega, A. Samoylov, 19-th International Scientific Conference Globalization and its Socio-Economic Consequences 2019 - Sustainability in the Global-Knowledge Economy. SHS Web Conf., 74, 2020. https://doi.org/10.1051/shsconf/20207402005

4. Ch. Watanabe, K. Naveed, Yu. Tou, Technological Forecasting and Social Change, 137, 226-240, (2018). https://doi.org/10.1016/j.techfore.2018.07.053

5. Ch. Watanabe, N. Naveed, P. Neittaanmäki, Technology in Society, 54, 168-188, (2018). https://doi.org/10.1016/j.techsoc.2018.05.002

6. L. Brandt, T. Rawski, Policy, Regulation and Innovation in China's Electricity and Telecom Industries, (2019). doi:10.1017/9781108645997

7. M. Tate, I. Bongiovanni, M. Kowalkiewicz, P. Townson, International Journal of Information Management 39, 186-198, (2018).

https://doi.org/10.1016/j.ijinfomgt.2017.11.008 
8. W. Sutherland, M. H. Jarrahi, International Journal of Information Management, 43, 328341, (2018). https://doi.org/10.1016/j.ijinfomgt.2018.07.004

9. I. G. Polyanskaya, V.V. Yurak Economy of the region, 13(2), 355-368. https://doi 10.17059/2017-2-3

10. A. Maffei, S. Grahn, C. Nuur, Procedia CIRP, 81, 765-770, (2019). https://doi.org/10.1016/j.procir.2019.03.191

11. Platform with access to financial markets: Cryptocurrencies. https://ru.investing.com/crypto/

12. H. B. Brahim, S. Hadoussa, Journal of of Management Research, 10(3), 1-13, (2018). https://doi.org/10.5296/jmr.v10i3.13103

13. N. Goridko, R. Nizhegorodtsev, IFAC-PapersOnLine, 51(11), 868-875, (2018). https://doi.org/10.1016/j.ifacol.2018.08.448

14. O. Popova, A. Starcev, M. Lunyakov, N. Fomenko, E3S Web of Conferences, 110, 01052 (2019). https://doi.org/10.1051/e3sconf/201911001052

15. D. Ahlstrom, J. L Arregle, M. A. Hitt, G. Qian, X. Ma, D. Faems, Managing technological, sociopolitical, and institutional change in the new normal, (2020). https://doi.org/10.1111/joms.12569

16. T. Genzorova, T. Corejova, N. Stalmasekova, Transportation Research Procedia, 40, 1053-1058, (2019). https://doi.org/10.1016/j.trpro.2019.07.147 